\title{
Conflitos não-mediáveis ou conflitos latentes? Aportes interdisciplinares para pensar a mediação em juízo na Lei 13.105/2015
}

\author{
Insoluble conflicts or latent conflicts? \\ Interdisciplinary contributions to think Brazilian \\ judicial mediation under Law 13.105/2015
}

Klever Paulo Leal Filpo ${ }^{1}$

\section{RESUMO}

$\mathrm{O}$ artigo privilegia uma abordagem interdisciplinar, fugindo ao hermetismo tradicional da dogmática no campo do direito. Tem por objetivo colocar sob discussão a mediação de conflitos introduzida no procedimento comum cível por força da lei 13.105/2015. Trata-se de uma aposta do legislador e do Poder Judiciário, no Brasil, para ofertar serviços judiciários mais eficazes à população, disseminar o uso da mediação a partir do Judiciário e ampliar as formas de acesso à justiça. Segundo os especialistas, esse método é capaz de educar as pessoas para lidarem de forma autônoma com os conflitos, o que promete, a longo prazo, reduzir o número de demandas judicializadas. O texto problematiza essa assertiva, lançando mão de subsídios fornecidos pela psicologia e pela antropologia. Relata algumas observações provenientes de pesquisa empírica qualitativa levada a efeito no Tribunal de Justiça do Rio de Janeiro. Desperta reflexões sobre os limites e obstáculos da mediação judicial, cujas características podem inibir a comunicação necessária para permitir que os conflitos sejam explicitados e adequadamente trabalhados pelos mediadores nas sessões ou audiências de mediação.

\section{PALAVRAS-CHAVE}

Mediação; judiciário; interdisciplinaridade; direito; Brasil; Lei 13.105/2015.

\begin{abstract}
The article focuses on an interdisciplinary approach, avoiding the traditional dogmatic hermetism of law studies. It aims to put under discussion conflict mediation introduced in Brazilian civil common procedure under the Law 13.105/2015. It tries to offer more effective judicial services to the population, spread the use of mediation and expand the means of access to justice. According to experts, this method is able to educate people to solve independently their conflicts, which promises to reduce the number of
\end{abstract}

1 Programa de Pós-graduação em Direito da Universidade Católica de Petrópolis. 
judicial demands. The text discusses this assertion, making use of subsidies provided by psychology and anthropology. It reports some observations from qualitative empirical research carried out at the Court of Rio de Janeiro. Arouses reflections on the limits and obstacles of judicial mediation, whose characteristics may inhibit the necessary communication that allows conflicts to be clarified and properly worked by mediators in mediation sessions or hearings.

\section{KEYWORDS}

Mediation; judiciary; interdisciplinarity; Brazil; Law 13.105/2015.

\section{INTRODUÇÃO}

O presente artigo é resultado de pesquisa em andamento no âmbito de Programa de Pós-Graduação em Direito sediado no estado do Rio de Janeiro, que tem uma de suas linhas de pesquisa dedicada ao processo e à efetivação da justiça e dos direitos humanos. No contexto dessa linha de pesquisa, tenho levado a efeito - em conjunto com alunos do mestrado, bolsistas PIBIC e Jovens Talentos da FAPERJ - investigações de natureza empírica, com abordagens qualitativas sobre diferentes mecanismos judiciais e extrajudiciais de administração de conflitos. Essas pesquisas buscam alargar a compreensão dos fenômenos jurídicos investigados por meio de um diálogo entre direito e antropologia, sobretudo pelo emprego do método etnográfico, que inclui entrevistas e observações das práticas judiciárias.

Nossas atenções estão voltadas para a mediação de conflitos desde que ela passou a ser empregada pelo Poder Judiciário, no Brasil, como um método destinado a auxiliar na solução das causas que lhe são submetidas para julgamento. Esse movimento iniciouse em 2010, com a Resolução 125 do Conselho Nacional de Justiça, inaugurando a Política Judiciária Nacional de tratamento adequado dos conflitos de interesse no âmbito do Poder Judiciário. E foi expandido recentemente com a previsão do uso da mediação em juízo, sob a forma de audiências de mediação, por força da Lei 13.105/2015, também conhecida como o Novo Código de Processo Civil (Novo CPC).

A mediação seria, na visão dos especialistas, um método mais célere, econômico e adequado (AZEVEDO, 2012) para a solução de conflitos, quando comparado com o processo judicial convencional. Além disso, também seria capaz de prevenir novos conflitos (TARTUCE, 2013, p. 44), e é esta promessa o centro de minhas atenções neste artigo. Nessa perspectiva, a mediação teria o condão de educar as pessoas envolvidas em um conflito, fazendo com que elas próprias repensem a relação conflituosa e passem a se comportar de forma diferente em relação aos seus adversários. É um argumento recorrente dos que defendem o uso da mediação de conflitos no Judiciário o de que aqueles que se submetem aos métodos mediativos dificilmente tornarão a ajuizar ações, já que, a partir daí, aprenderão a solucionar sozinhos as suas disputas, sem necessitar do auxílio do Estado-juiz.

A utilização da mediação em juízo passa a representar, portanto, uma aposta do legislador e do Poder Judiciário na oferta de serviços judiciários mais eficazes à população. Em médio ou longo prazo, a sua disseminação se propõe a reduzir o número de demandas judicializadas. Essa é apresentada como uma certeza pelos especialistas em mediação de conflitos. 
O que pretendo, neste paper, é problematizar essa assertiva. Lançando mão de subsídios da antropologia (por intermédio da abordagem etnográfica presente nos casos aqui relatados) e da psicologia (que encara os conflitos e o seu tratamento de modo diverso daquele que é usual para os juristas), espero, em primeiro lugar, identificar e compreender o mecanismo da mediação no ponto em que ela se propõe a evitar o desdobramento dos conflitos e a eventual multiplicação das ações a eles correspondentes, destacando também as dificuldades e perplexidades reveladas pela observação de casos de emprego da mediação em juízo. Isso parece importante, especialmente com o advento do Novo CPC que, dentre outros aspectos, pretende disseminar o uso da mediação a partir do Judiciário e ampliar as formas de acesso à justiça.

Ao mesmo tempo, o artigo tem a pretensão de provocar uma reflexão ou, antes ainda, de ensaiar uma abordagem interdisciplinar sobre o tema, o que parece bastante oportuno e até necessário, como buscarei demonstrar no item seguinte.

\section{QUANDO A INTERDISCIPLINARIDADE É NECESSÁRIA}

Há uma tendência dos juristas de encararem a administração de conflitos como um assunto propriamente jurídico, em sentido estrito, cujo equacionamento demandaria, tão somente, a habilidosa operação do sistema de justiça e das leis vigentes. É o que vem acontecendo com a mediação de conflitos, que agora tem tratamento legislativo, sendo encarada no meio jurídico como não mais do que uma ferramenta a ser utilizada para debelar os processos, perspectiva esta que ignora (e até mesmo repele) outras abordagens, para além do aspecto normativo.

Fonseca (2005) há décadas vem sustentando que "a visão jurídico-tecnicista, representada pela doutrina dogmática do direito, primou por excluir das análises jurídicas qualquer elemento dito não-jurídico, esperando desse modo garantir a cientificidade do direito". Segundo a mesma autora (op. cit., p. 11-12), os juristas e a ciência do direito teriam muito a ganhar com o exercício da interdisciplinaridade, porque se propõe a romper com o hermetismo que é uma característica da formação jurídica no Brasil. O estudo do direito, sobretudo na graduação, tende a voltar-se para si mesmo, sem enxergar benefícios ou, antes, sem conseguir desenvolver a habilidade de estabelecer um diálogo com outras ciências.

A expressão “interdisciplinaridade", para FONSECA (2005, p. 26), diz respeito à "aproximação de pontos de vista de diferentes disciplinas a respeito do mesmo objeto, de modo a obter-se uma compreensão deste, não como exclusivo desta ou daquela ciência, mas como realidade multifacetada". É algo importante, já que o direito é uma realidade com várias faces, que parecem multiplicar-se quando ele é aplicado na prática, como um mecanismo de administração de conflitos concretos.

Fragale Filho (2005), em artigo no qual procura demonstrar "quando a empiria é necessária", aponta a utilidade das abordagens e metodologias interdisciplinares, sobretudo sócio-jurídicas, dos temas de interesse jurídico. Sustenta que a ausência da pesquisa empírica acaba impedindo a habilidade de desenvolver uma crítica aos institutos jurídicos, naturalizando, por exemplo, a ideia de que "o Estado seria o horizonte insuperável de organização da vida humana" (op. cit., p. 329), o que, por tabela, acaba impedindo que sejam observadas e compreendidas as falhas e limitações desse mesmo Estado, suas leis e instituições. Conclui que "o concreto está por todos os lados, à espera de um olhar crítico que nos ajude a entender a importância da regulação e das tecnologias 
jurídicas" (op. cit., p. 334), e propõe o uso da pesquisa empírica como estratégia para alargar o campo de investigação científica no direito.

A despeito dessas falas, a dogmática persiste sendo a tônica da formação dos juristas brasileiros. Inúmeras iniciativas já foram levadas a efeito por pesquisadores e instituições para romper com esse paradigma. Por exemplo, desde 2004 as Diretrizes Curriculares Nacionais do Curso de Graduação em Direito, instituídas pela Resolução 09/2004 do Conselho Nacional de Educação, inseriram no currículo dos cursos jurídicos conteúdos de antropologia e psicologia. Estes, somados àqueles já existentes de sociologia, ética, ciência política, história, economia (FONSECA, 2005, p. 12), estariam propensos a fomentar nos futuros bacharéis a habilidade de encarar os problemas jurídicos de forma multifacetada, dialogando com as ciências humanas e sociais. Mas esse parece ser um processo longo e, de certa maneira, algo não tão fácil de ser assimilado pelo estudante de direito, nos cursos de formação - sendo exercitada com maior frequência em alguns cursos de pós-graduação em sentido estrito.

A impressão que tenho como professor de "tópicos de ciências humanas e sociais" em dois cursos de bacharelado em direito, reforçada pelas impressões colhidas de colegas professores de disciplinas equivalentes em outras instituições, é de que essas disciplinas são, de certo modo, repelidas pelos estudantes, ao mesmo tempo em que, em geral, são consideradas de menor importância até mesmo pelas coordenações de curso. São chamadas de "disciplinas propedêuticas". Sabe-se que a expressão "propedêutica" é originária do grego e diz respeito a um curso ou a parte de um curso que fornece elementos básicos para o prosseguimento dos estudos, revestindo-se, por isso mesmo, de importância e certa essencialidade, como é próprio da base de qualquer estrutura.

Contudo, no espaço dos cursos jurídicos, sobretudo os que se revestem de tendências mais dogmáticas ("cada curso tem uma cara", como me explicou um colega, experiente professor), tenho a impressão de que a expressão "propedêutica" ganha equivocada conotação pejorativa, para indicar aquelas disciplinas que, na visão dos alunos "não têm nada a ver com o direito"; "não contribuem para a aprovação no concurso público ou o exame de Ordem"; e que precisam ser logo ultrapassadas "para chegar ao segundo ou terceiro períodos do curso quando se começa a estudar o direito de verdade". Com efeito, existe certa dificuldade em identificar aplicação prática-jurídica para os elementos fornecidos pelas disciplinas propedêuticas, o que parece contribuir para um desinteresse generalizado a seu respeito. É evidente a predominância da formação voltada para a lida forense em detrimento da formação científica, nesses cursos.

Embora sem desprezar, obviamente, a importância das abordagens dogmáticas, sobretudo para os profissionais do direito (vulgarmente denominados "operadores": juiz, promotor, advogado, defensor público, dentre outros), no aspecto científico é preciso investir no diálogo entre o direito e outras ciências. Sobretudo quando o objeto da pesquisa é complexo e a sua compreensão ou "operação" demanda a interlocução de múltiplos saberes, como ocorre com a mediação de conflitos. A maior prova disso é o fato de o Novo CPC ter autorizado que qualquer profissional de nível superior, devidamente capacitado, possa desempenhar o papel de mediador em juízo. Esse aspecto, além de ser uma convocação para a interdisciplinaridade, exigirá muito dos profissionais envolvidos nessa atividade dentro do fórum, juristas e não-juristas, em uma interação que ainda poderá ser objeto de muitas investigações empíricas voltadas para descrevê-la e compreender as dificuldades e impasses que surgirão a partir daí.

É bem verdade que a tentativa de estabelecer esse diálogo não é simples. Para além das resistências já mencionadas nos parágrafos anteriores, há também uma 
dificuldade essencial: é que, embora haja um clamor pela ampliação da interdisciplinaridade em todas as áreas (ele não aparece apenas no campo do direito, mas também na educação, na psicologia, na medicina, dentre outras), não existe um roteiro pré-determinado para colocá-la em prática. Não existem manuais capazes de dizer como disciplinas diferentes podem dialogar, simplesmente porque determinismos não são possíveis aqui. Por outro lado, esse diálogo exige que cada um abandone sua zona de conforto. Exige, por exemplo, que juristas, antropólogos, sociólogos, psicólogos, dentre outros, estejam dispostos ao encontro e ao diálogo, o que não parece ser tarefa fácil, nem uma prática habitual.

Tenho pensado em uma interdisciplinaridade a ser construída, por tentativa e erro, a partir de temas ou objetos de interesse comum. As múltiplas abordagens sobre um determinado objeto podem proporcionar pontos de encontro inovadores entre diferentes perspectivas. No caso deste ensaio, a proposta é fazer dialogarem com o direito, a antropologia e a psicologia em torno de um tema de interesse comum, que é a mediação de conflitos, no contexto do Poder Judiciário.

Vale dizer que a mediação se revestiu, nesse novo Código, do formato de uma audiência, a ser presidida pelos mediadores capacitados pelo Tribunal, observando regras procedimentais próprias e, até mesmo, tendo como norte o Manual de Mediação adotado pelo Ministério da Justiça (AZEVEDO, 2012). Tudo isso parece revesti-la de forte caráter dogmático. Contudo, essa estrutura normativa não será capaz de assegurar, por si só, o sucesso na utilização desse método em juízo. Nem mesmo a natureza compulsória da via da mediação (a ausência injustificada à sessão de mediação é agora caracterizada, na lei, como um ato atentatório à dignidade da justiça!) pode garantir que as partes submetidas a essas audiências perceberão melhorias na sua capacidade de dialogar.

Melhor dizendo: a lei pode até determinar que a parte compareça às sessões de mediação; pode regular a atuação e a remuneração dos mediadores; pode estabelecer mecanismos de controle estatístico para aferir o sucesso da mediação em juízo, dentre outros. Mas não pode determinar que as pessoas submetidas à mediação celebrem acordos, ou que fiquem satisfeitas com a experiência da mediação, ou ainda que melhorem a sua capacidade de comunicação por intermédio das técnicas mediativas. A perspectiva normativa ou dogmática é apenas uma das que pode se ocupar de um determinado tema ou fenômeno. Ela não dá conta, sozinha, de permitir a sua adequada compreensão.

Isso pode explicar a frustração dos juristas diante da falência ou ineficácia de determinados institutos, que são muito bem concebidos do ponto de vista da lei e da doutrina, mas não resistem quando submetidos à prova da realidade. Um exemplo disso são os Juizados Especiais Cíveis, os quais, segundo alguns estudos de natureza empírica (v. g. AMORIM, 2003), não conseguiram desempenhar o papel ao qual se destinavam, sobretudo pelo grande número de demandas e pela ineficácia das audiências de conciliação - já que nelas raramente o acordo é obtido, tendo se tornado um problema para a administração dos tribunais estaduais.

No caso da mediação judicial, a tomada de decisões a seu respeito parece exigir que seja examinado sob outras perspectivas. E é aqui que a interdisciplinaridade parece ser necessária. Sem ela, corre-se o risco de que se torne mais uma iniciativa frustrada no campo da administração de conflitos pelo Judiciário, reforçando a distância entre a norma e as teorias jurídicas e a sua prática. 


\section{COMUNICAÇÃO E CARÁTER PREVENTIVO DA MEDIAÇÃO}

A adoção da mediação em juízo se justifica por três argumentos básicos. Esses argumentos estão presentes nos livros que tratam do tema (por exemplo, BARBOSA, 2003 e AZEVEDO, 2012) e também nas falas dos atores, sobretudo profissionais da mediação (mediadores e juízes supervisores dos Centros de Mediação do TJERJ), com os quais tive oportunidade de interagir durante meu trabalho de campo.

Em primeiro lugar, existe a ideia de que a mediação seria uma forma de dar solução rápida aos conflitos de interesse, isto é, encerrá-los com mais celeridade do que aconteceria caso trilhassem o caminho convencional. Essa assertiva seria verdadeira especialmente naqueles casos em que as mesmas partes estão envolvidas em diferentes conflitos, já que todos eles, e os processos derivados, poderiam ser extintos simultaneamente mediante um eventual acordo obtido na mediação. O discurso é de que, por se tratar de um método informal, tal acordo não precisaria ficar restrito aos termos de uma ação específica, podendo ser mais flexível e abrangente, tudo dependendo da vontade das partes.

Em segundo lugar, há a percepção de que o Judiciário está abarrotado de processos, sendo necessário e urgente encontrar solução para esse problema. Na medida em que a opção de investir em infraestrutura não foi cogitada nos espaços de discussão abordados durante esta pesquisa, a mediação se apresentaria como uma das alternativas possíveis, ressaltando, especialmente, que os mediadores judiciais trabalham como voluntários, atualmente, sem receber nenhuma remuneração, o que a torna econômica.

Finalmente, existe o pensamento de que o acordo obtido por meio da mediação seria capaz de dar uma solução de melhor qualidade (mais adequada) para os conflitos de interesse do que aquela imposta pela sentença. Se o conflito é das partes, seriam elas as mais qualificadas para chegarem a uma solução adequada, e não o juiz. A opção pela mediação daria aos mediandos a oportunidade de afastarem, em termos, a intervenção do terceiro e reassumirem o protagonismo na administração da disputa.

Conclui-se que a mediação, da forma como é apresentada na literatura, seria supostamente um mecanismo mais célere, econômico e adequado de colocar ponto final em conflitos de interesse, quando comparado com a solução oferecida pela via estataljudiciária tradicional.

Ao lado desses argumentos centrais surge outro, que diz respeito aos efeitos da mediação para o futuro, que é o centro de minhas atenções neste artigo. Nessa perspectiva, a mediação teria o condão de educar as pessoas envolvidas em um conflito, fazendo com que elas próprias repensem a relação conflituosa e passem a se comportar de forma diferente em relação aos seus adversários.

Para Tartuce (2003, p. 44), "a retomada da comunicação é a finalidade maior da mediação". A autora explica que "uma mediação bemsucedida é aquela em que, promovida eficientemente a facilitação do diálogo pelo mediador e aparadas as arestas, as partes podem retomar a comunicação de forma adequada, passando a conduzir suas relações de forma consensual". A mediação teria, assim, um caráter preventivo, isto é, uma aptidão de prevenir novos conflitos de interesse.

Warat (2004) também é um dos autores que destacam esse papel educativo da mediação. Se bem que, a princípio, ele não a concebia como um instrumento processual, mais uma "ferramenta" colocada à disposição dos profissionais do direito para debelar conflitos de interesse. Nem a enxergava como um procedimento repleto de regras rígidas a serem observadas ou de relatórios a serem preenchidos pelos mediadores. Ao contrário, 
não se mostrava simpático a essa iniciativa, preferindo pensar a mediação como um processo social e comunitário, relacionado à reafirmação dos direitos humanos.

Não obstante, o potencial educativo da mediação poderia evitar o ajuizamento de novas ações, originadas a partir do mesmo conflito, pois as partes conseguiriam dar conta dele sem ter que recorrer ao Judiciário. Nos discursos dos entusiastas da mediação, essa seria uma certeza. Ao meu sentir, trata-se de uma hipótese que pode, ou não, ser confirmada, a depender do caso e da forma como o conflito for trabalhado na mediação. A ser comprovada essa hipótese, a mediação tornar-se-ia extremamente útil para o Judiciário. Poderia evitar, no fórum, as chamadas "reincidências" que se caracterizam, na prática, pelo ajuizamento de inúmeras ações, de diferentes matizes (por exemplo, uma ação de divórcio que se desdobra em regulação de visita aos filhos e pedido de concessão medida protetiva de afastamento). Nessa medida, poderia até mesmo contribuir para o controle do "estoque" de processos, reduzindo a entrada de processos novos e auxiliando para solucionar os já existentes.

De todo modo, para que a mediação possa produzir efeitos benéficos para o futuro, faz-se necessário que se estabeleça, durante as sessões de mediação, a comunicação entre as partes. Nessa comunicação, os especialistas (v. g. TARTUCE, 2013; AZEVEDO, 2012) recomendam que as questões controvertidas sejam colocadas às claras. Para isso se faz necessário investir na formação dos mediadores e conceder tempo para que a mediação possa ser aplicada de forma adequada, assegurando, assim, o sucesso na explicitação da controvérsia entre as partes, de modo a permitir que seja adequadamente trabalhada pelos mediadores nas sessões.

\section{CONFLITOS LATENTES E CONFLITOS MANIFESTOS}

O alargamento da compreensão sobre o emprego da mediação, seus métodos, utilidade e limitações, parece exigir, como já afirmei acima, que se estabeleça um diálogo com outras ciências. Aqui tentarei ensaiar um diálogo com a psicologia a respeito do tema da administração dos conflitos. Mais adiante utilizarei, também, alguns subsídios da antropologia para completar esse diálogo.

No meio jurídico, a existência dos conflitos é, em geral, encarada de forma negativa, representando uma espécie de "doença" social, para a qual o direito seria a "cura". Não é raro encontrar, em textos jurídicos, referências a essa ideia. Cavalieri Filho (1997), ao tratar da função social do direito, explica que:

O conflito gera o litígio e este, por sua vez, quebra o equilíbrio e a paz social. A sociedade não tolera o estado litigioso porque necessita de ordem, tranquilidade, equilíbrio em suas relações. Por isso, tudo faz para evitar ou prevenir o conflito, e aí está a primeira e principal função do direito - Prevenir conflitos: evitar, tanto quanto possível, a colisão de interesses (CAVALIERI FILHO, 1997, p. 15).

Essa percepção é bastante diferente daquela apresentada por alguns textos escritos por psicólogos. Por exemplo Maldonado (2008), que enxerga os conflitos de forma mais positiva, como sugere o próprio título do livro aqui considerado: "O Bom Conflito: juntos buscaremos a solução".

Sustenta a autora (2008, p. 13) que os conflitos fazem parte da vida de todos e podem acontecer até nos relacionamentos mais harmônicos. Essa harmonia é 
consequência de inúmeros "acordos" que são feitos diariamente pelas pessoas em diferentes lugares e contextos: na família, na escola, no trabalho. Contudo, apesar de toda essa habilidade e prática de lidar com as divergências, eventualmente o conflito é inevitável, sendo desejável, segundo a autora, aprender a resolvê-lo de modo mais eficaz.

Ainda segundo a autora (MALDONADO, 2008, p. 22), os conflitos são geralmente explicáveis pelo choque entre diferentes maneiras de enxergar a mesma situação, decorrentes de diferentes "visões de mundo". Estas seriam "estruturas que contêm nossos valores, crenças e suposições, e que influenciam nossa identidade (a maneira como nos vemos)". A partir dessas estruturas são construídos os significados da vida e relacionamentos de cada um, resultando em combinações que são diferentes de uma pessoa quando comparada com a outra. Por esse motivo, Maldonado (2008, p. 22) defende que "a solução eficaz para os conflitos precisa levar em conta essas diferenças, sejam elas conscientes ou não".

A autora sugere formas diversificadas de tratamento de conflitos. De maneira sintética, propõe que as diferenças de pontos de vista sobre uma mesma questão, sendo origem de muitos conflitos, exigem comunicação clara para que possam ser construídos caminhos de consenso os quais, ainda que não levem ao desaparecimento do conflito, podem permitir uma convivência pacífica entre as pessoas ou grupos envolvidos na disputa. Nesse ponto, o discurso da autora guarda bastante afinidade com aquele encontrado em textos que pretendem estimular o emprego da mediação como método extrajudicial ou judicial de administração de conflitos.

Essa comunicação seria aperfeiçoada pela intervenção de um terceiro facilitador (MALDONADO, 2008, p. 142), que a autora chama de mediador em algumas poucas passagens do texto - preferindo a expressão facilitador por ser mais abrangente e englobar vários atores (professores, pais, agentes públicos, líderes comunitários, dentre outros) do que a expressão mediador (que pode significar tão somente os que exercem a mediação como uma atividade profissional).

Um ponto importante do texto aqui considerado é aquele em que a autora estabelece uma distinção entre "conflitos latentes" e "conflitos manifestos". Segundo o dicionário Michaelis da língua portuguesa, manifesto deriva do Latim manifestu; pode ser um adjetivo, significando a qualidade daquilo que é claro, evidente, público, notório. Por outro lado, ainda segundo o léxico, latente é o antônimo de "claro". É adjetivo que diz respeito àquilo que não se vê, que está oculto, dissimulado ou subentendido. Pode-se dizer latente da "atividade ou caráter que, em certo momento, não se manifesta, mas que é capaz de se revelar ou desenvolver quando as circunstâncias sejam favoráveis ou se atinja o momento próprio para isso".

De acordo com Maldonado (2008, p. 23),

[...] muitas vezes, o conflito existe, mas não é percebido nem reconhecido: é o conflito latente, que transparece o clima de tensão e insatisfação, intensificando a frustração, a desconfiança e a desarmonia nos vários níveis em que se instala (intrapessoal, interpessoal ou organizacional).

Os conflitos latentes apresentam potencial para o surgimento de disputas difíceis de serem equacionadas, já que somente são percebidos os seus desdobramentos. Ao contrário, o conflito manifesto é visível e palpável, facilitando sua compreensão e a busca de soluções. O conflito latente gera muitas correntes subterrâneas (Maldonado, 2008, p. 
23) porque as pessoas envolvidas preferem "fazer de conta que o problema não existe, não manifestam claramente seu desconforto ou desagrado e pensam que falar sobre ele é mais perigoso do que mexer em casa de marimbondos".

Nessa medida, parece ser importante para o êxito das sessões de mediação que haja tempo e disposição para permitir que os conflitos sejam explicitados. Apenas dessa forma podem tonar-se palpáveis e, por isso mesmo, tratáveis por meio das técnicas inerentes à mediação, de modo a proporcionar benefícios para o futuro, prevenindo desdobramentos e reincidências.

\section{CONFLITOS MEDIÁVEIS E NÃO-MEDIÁVEIS: ESTUDO DE UM CASO}

Esse processo dialógico a que me referi no item anterior, contudo, demanda muito tempo e grande esforço por parte dos mediadores, observando-se variação no seu desenvolvimento e resultados, quando comparado um caso com o outro. Não se trata de um procedimento formalizado, como é o processo judicial. Por isso mesmo a mediação é geralmente concebida como um método de administração de conflitos extrajudicial, informal, e que não observa regras rígidas, dependendo muito mais da vontade das partes para definirem a forma como vai se desenrolar, o que interessa ou não interessa ser tratado ali, como e quando acontecerão os encontros, dentre outros aspectos. Nem mesmo se costuma conceber uma mediação "presidida" por uma autoridade, já que a sua simples presença pode ser capaz e inibir a autonomia das partes que se pretende fomentar por meio da mediação (KESSLER, 2009).

Essa informalidade e o protagonismo das partes quanto ao conteúdo e forma das sessões parece ser um fator determinante para o êxito da mediação. E não é isso, a princípio, o que tende a ocorrer quando ela é colocada em prática no Poder Judiciário. Essa inserção da mediação nos espaços forenses exige, ao contrário disso, uma reconfiguração das técnicas e procedimentos da mediação, para adequá-la ao processo judicial, com o qual se espera que ela venha a interagir.

As observações empíricas a que vou me referir foram feitas no Tribunal de Justiça do Rio de Janeiro (TJERJ) entre os anos de 2010 e 2013, nos espaços em que a mediação vinha sendo aplicada, à época, sob a égide da Resolução 125 do CNJ, que determinou a criação dos primeiros centros de mediação de conflitos. Meu objetivo, durante a pesquisa, foi de compreender de que forma vinha sendo colocada em prática a mediação de conflitos dentro do fórum, muitas vezes no bojo de processos que já estavam em andamento, e como o chamado "processo de mediação" (AZEVEDO, 2012) poderia dialogar com o processo judicial convencional, bem com os impasses que decorriam dessa aproximação entre dois métodos de administração de conflitos tão distintos.

Um dos casos observados durante a pesquisa de campo tinha como protagonistas um casal separado há alguns anos, os quais ajuizaram, inicialmente, uma ação de dissolução de união estável, que culminou com um acordo homologado pelo juiz. Dentre as cláusulas do acordo ficou ajustado que a guarda dos dois filhos do casal caberia à mãe, com visitação livre. E que esta, juntamente com os seus filhos, deveria deixar o lar conjugal: uma casa simples, construída mediante o esforço conjunto.

O acordo não surtiu, contudo, os efeitos práticos desejados. Os filhos deixaram de visitar o pai e evitavam contato com ele. Por outro lado, a casa não foi desocupada, já que a mulher alegava não ter para onde ir, nem recursos para comprar ou alugar outro imóvel, enquanto o homem tinha a opção de retornar para a casa de seus pais. O Cumprimento do 
acordo esbarrava, portanto, em aspectos afetivos e comportamentais (no tocante à visitação dos filhos pelo pai) e econômico-financeiros (no tocante à desocupação da casa). $\mathrm{O}$ aspecto interdisciplinar do conflito parecia evidente. Isso fez com que o conflito se intensificasse e que fossem ajuizadas outras novas ações, a saber: (1) regulamentação de visitas, pelo pai; (2) cumprimento (execução) da sentença pelo pai, que pretendia ver a casa desocupada.

Por fim, em um momento de discussão mais acalorada, as partes se atracaram e causaram lesões corporais recíprocas, de natureza leve, que os levou à Delegacia de Polícia e, na sequência, ao Juizado de Violência Doméstica e Familiar Contra a Mulher. Essa ação não foi levada adiante, já que a mulher, em audiência designada pelo juízo, acabou se retratando da representação oferecida contra o ex-companheiro, que constava dos autos como "autor do fato" criminoso.

Percebendo que o caso era bastante complexo e envolvia muitas emoções mal resolvidas, entendeu o juiz de família perante o qual tramitava o pedido de regulamentação de visitas por enviá-lo ao centro de mediação da comarca. Acreditou o magistrado que as partes necessitavam melhorar a sua capacidade de comunicação, o que foi dito pelo juiz durante a audiência na qual ocorreu esse encaminhamento.

Esse caso foi por mim acompanhado pessoalmente, durante o trabalho de campo. Seu tratamento demandou seis encontros presenciais entre as partes, as sessões de mediação, cada qual com aproximadamente duas horas de duração, as quais foram conduzidas por dois mediadores do Tribunal. Ficou patente a dificuldade de comunicação existente entre os mediandos que, ao início, sequer trocavam olhares. No decorrer das sessões, observei que o diálogo foi sendo aperfeiçoado, mediante suaves e habilidosas intervenções dos mediadores. Ao final, o resultado positivo da mediação pode ser verificado concretamente pelo restabelecimento do contato do pai com os filhos.

Contudo, o aspecto da desocupação da casa, que fora ajustado em acordo anterior, devidamente homologado pelo juízo competente, foi propositalmente evitado pelos mediadores. Toda vez que o assunto vinha à tona a discussão entre os mediandos se intensificava. Por isso, como um observador externo, entendi que essa questão estava no centro da animosidade, porque despertava muitas discussões e brigas, sendo estas assistidas, muitas vezes, pelos filhos. Estes, sendo obrigados a vivenciar esses momentos desagradáveis, acabavam saindo em defesa da mãe, a qual não tinha para onde ir, o que justificava a resistência à pessoa do pai. Essas informações apareceram durante as sessões de mediação. Contudo, o problema da casa não foi enfrentado pelos mediadores.

Quando perguntei por que motivo não iria insistir nessa questão, um dos mediadores explicou que há conflitos que são mediáveis e outros que não são mediáveis, ou seja, que não comportam uma decisão debatida entre as partes, mas que exigem a intervenção de um terceiro, no caso, o juiz, que irá decidir por meio da sentença. Entendi dessa explicação que, quando as partes apresentam-se irreconciliáveis, isto é, são refratárias a qualquer tipo de composição de interesses, o conflito é considerado "nãomediável”, caso em que a decisão dada pelo juiz é a única saída. Isso pode acontecer de forma parcial, quando não convém às partes ou aos mediadores que algum aspecto da disputa seja trabalhado nas sessões de mediação, como aconteceu com esse casal em relação à casa.

$\mathrm{Na}$ minha percepção, contudo, o enfrentamento dessa questão pelos mediadores foi uma decisão dos mediadores que levou em conta, essencialmente, o fator tempo. Ocorre que, enquanto aquela mediação se desenrolava, o processo de regulamentação de visitas que lhe dera origem estava paralisado, aguardando o resultado da mediação para 
que pudesse ser extinto em razão do acordo obtido ou, em caso de insucesso, para que pudesse ter prosseguimento. Os mediadores necessitavam "prestar contas" do processo ao juiz. Não havia condições, portanto, de levar adiante a discussão. A questão da casa, que parecia ser uma questão central e que poderia ser trabalhada durante as sessões de mediação, foi propositalmente contornada.

Esse aspecto já havia sido abordado por RANGEL (2013), antropólogo que conduziu pesquisa etnográfica em Juizados Especiais de Niterói-RJ, utilizando o método da observação participante. Observando sessões de mediação e audiências de conciliação, sua pesquisa explicitou que a verdadeira origem de alguns conflitos permaneceu invisível em mediações por ele observadas no campo, porque os mediadores entendiam que não deviam adentrar em certos assuntos polêmicos como, por exemplo, questões de natureza religiosa.

Segundo o autor, durante o seu trabalho de campo, pareceram ser comuns brigas entre vizinhos que professam ou praticam religiões distintas. Em um dos casos relatados, um evangélico que pretendia escutar músicas evangélicas em sua casa sentiu-se incomodado pelos ruídos que advinham de um centro espírita, situado nas proximidades. Isso fez com que os vizinhos entrassem em discussões acalorados que resultaram, até mesmo, em ameaças recíprocas. Estas ameaças foram encaminhadas ao Juizado Especial Criminal da localidade e o juiz encaminhou o caso para a mediação.

Durante o tratamento do caso no centro de mediação, RANGEL (op. cit.) observou que o aspecto da tolerância religiosa era evitado pelos mediadores, embora parecesse relevante. Talvez sob o argumento de o Estado é laico, e que não competia ao Judiciário decidir sobre isso. Aparentemente, sem trabalhar esse tema nas sessões, havia grande chance de novos conflitos ocorrerem entre os vizinhos que praticavam religiões distintas. Esse exemplo sugere uma tendência de que, em se tratando de mediação judicial, alguns temas polêmicos, desgastantes, ou que demandem muito tempo, sejam contornados.

Uma orientação comum dada pelos mediadores aos mediandos nas sessões que observei se refere à necessidade de "esquecer o passado e olhar para o futuro". O objetivo declarado dessa orientação é estimular as partes a construírem um relacionamento de melhor qualidade a partir da experiência da mediação. Mas ela também dá margem a que certos aspectos e desdobramentos dos conflitos, e até mesmo a sua origem, possam ser deixados de lado e não enfrentados durante as sessões de mediação, permanecendo ocultos.

Essa orientação parece ter o objetivo de controlar a mediação que se realiza em espaços judiciários, para conformá-la ao processo judicial que é formal e controlado no tempo. Contudo, nos casos aqui relatados, os conflitos permaneceram latentes, não chegando a ser adequadamente explicitados, o que torna difícil ou mesmo impossível que a mediação proporcione o objetivo de prevenir reincidências, o surgimento de novos conflitos e o ajuizamento de novas ações.

\section{A MEDIAÇÃO DE CONFLITOS NO NOVO CPC}

Os casos relatados no item anterior foram observados durante o emprego da Resolução 125 do CNJ pelo TJERJ. Mas as perspectivas não parecem ser diferentes para aquilo que se avizinha com a entrada em vigor do Novo CPC.

A criação de uma oportunidade de diálogo entre as partes, auxiliadas por um profissional capacitado e disposto a melhorar a sua comunicação, tem sido enxergada 
pelos processualistas como um dos grandes avanços da Lei 13.105/2015. O novo procedimento comum cível (destinado às causas cujas especificidades não recomendam a observância de um rito especial) contempla a busca pelo consenso por meio da conciliação e da mediação. Trata-se de reservar um momento especial dedicado para tentar restabelecer, entre as partes, um canal de comunicação.

Com o Novo CPC, a parte autora deverá informar no corpo da petição inicial se deseja ou não submeter-se ao procedimento de mediação (art. 319, VII). Esse é um requisito da petição inicial. Caso a parte não o atenda, deverá completá-la por determinação do juiz (art. 321) sob pena de indeferimento da inicial. Essa manifestação é, portanto, obrigatória.

O juiz, por sua vez, ao despachar a petição inicial, verificando que todos os requisitos essenciais foram atendidos, deverá designar uma audiência de mediação ou de conciliação (art. 334). A primeira opção fica reservada, a princípio, para aqueles casos em que houver vínculo anterior entre as partes ( $\$ 3^{\circ}$ do artigo 165). Essa audiência de mediação somente não acontecerá se ambas as partes, tanto o autor como o réu, informarem que não estão dispostos a buscar uma solução consensual, ou se a matéria em discussão não comportar composição (em tese, nas ações que tratam de direitos indisponíveis).

Ainda de acordo com novo Código, o mediador é o profissional que vai atuar nesses casos, auxiliando as partes a "compreender as questões e os interesses em conflito, de modo que eles possam, pelo restabelecimento da comunicação, identificar, por si próprios, soluções consensuais que gerem benefícios mútuos" (art. 165).

No que se refere às ações litigiosas de família, o Código de 2015 também inovou, quando comparado com o Código de 1973, ao inserir no Título III, do Livro I da Parte Especial, que trata dos procedimentos especiais, um Capítulo para cuidar especificamente das ações de família (Capítulo X). As disposições contidas nesse capítulo são destinadas a regular apenas os processos contenciosos de divórcio, separação, reconhecimento e extinção de união estável, guarda, visitação e filiação. E ainda, de forma subsidiária em vista das leis especiais aplicáveis, as ações de alimentos e aquelas que versem sobre interesses de crianças e adolescentes. A mediação é apresentada com uma forma ideal de enfrentamento das questões de família (cf. CEZAR-FERREIRA, 2007)

Contudo, a despeito das boas intenções do legislador e da expectativa e entusiasmo que essa inovação vem despertando, pode-se indagar se todo esse formalismo de que a mediação foi impregnada, no contexto do Novo CPC, para ajustar-se ao formato do rito processual (judiciário) nele regulado, não é, na verdade, incompatível com a necessidade de criar, no espaço da mediação, oportunidades de diálogo e a explicitação dos conflitos, que parece ser necessária para que o método se torne eficaz.

Uma das questões mais importantes diz respeito ao tempo que se pode dedicar à mediação em juízo. No tratamento dado pelo CPC a mediação é uma audiência, a ser conduzida pelos mediadores, em intervalos que não podem ser inferiores a 20 minutos. Logo, um mediador com a pauta sobrecarregada, desejando cumprir a lei, sentirá necessidade de marcar as audiências de mediação de 20 em 20 minutos. Nesse contexto, é evidente que os diálogos e o resgate da comunicação ficarão bastante comprometidos.

Esse aparente paradoxo que se estabelece entre as exigências temporais da mediação e a previsão contida no Novo CPC torna-se mais ameno no contexto das ações de família. Para esses conflitos o código admite a possibilidade de serem realizadas várias sessões de mediação (art. 696), caso necessário, assegurando melhores condições para o tratamento do conflito. Mas ainda existe uma recomendação específica para prevenção 
do risco de perecimento do direito, ou seja, uma advertência no sentido de que o tempo investido não pode ser tão longo que possa vir a prejudicar o direito discutido na causa específica.

Outro fator complicador constatado durante a pesquisa de campo é o problema da infraestrutura. Por se tratar de algo novo, o tribunal considerado na pesquisa, assim como deve ocorrer com outros ao redor do país, não estava estruturado adequadamente para colocar em prática a mediação dentro dos processos. Nem mesmo existem mediadores capacitados em quantidade suficiente e devidamente remunerados para essa atividade. Isso faz supor que os poucos mediadores em atividade estarão sobrecarregados, impedindo que possam se aprofundar no tratamento dos conflitos que lhe são submetidos, até mesmo por razões práticas.

\section{CONCLUSÃO}

Neste ensaio, procurei estabelecer um diálogo interdisciplinar entre o direito, a psicologia e a antropologia, a fim de pensar o instituto da mediação de conflitos agora introduzido no processo civil brasileiro por força da Lei 13.105/2015, conhecida como Novo CPC.

Dentre todos os aspectos positivos da mediação de conflitos, apontados pelos diferentes autores citados no decorrer do texto, um deles mereceu especial atenção: a promessa de que a mediação tem um caráter preventivo, com aptidão para fazer com que as pessoas aprendam a lidar com os conflitos de forma construtiva e autônoma, o que pode evitar o ajuizamento de novas ações. Nessa medida, seria positivo para o Judiciário e para a sociedade como um todo.

Numa aproximação da psicologia, verifiquei que o conflito pode ser algo positivo, se adequadamente trabalhado pelas partes com o auxílio de um facilitador, por se tratar de oportunidade de aperfeiçoamento pessoal. Ao contrário do que ocorre na percepção jurídica tradicional, para a psicologia o surgimento dos conflitos na vida social é inevitável e eles não devem permanecer camuflados. Necessitam ser explicitados, manifestados. Desconhecido e perigoso é o conflito latente, por ser intratável. Só se pode tratar o conflito manifesto.

Por outro lado, as experiências empíricas relatadas no texto, a partir de uma perspectiva antropológica, demonstraram que, na mediação judicial, as categorias do que $e ́$ ou não é mediável são empregadas pelos profissionais a quem compete dirigir as atividades de mediação dentro do campo, mas não têm um sentido determinado que pudesse permitir uma uniformidade no tratamento dos diferentes casos. Trata-se de uma decisão tomada por esses profissionais que, na prática, lançando mão de avaliações subjetivas, preferem prosseguir nas tentativas de mediar o conflito ou, pelo contrário, preferem encerrar o processo de mediação e permitir que processo judicial retome o seu curso.

Do ponto de vista jurídico, isso causa alguma perplexidade. Pode-se admitir que, ocasionalmente, essa prática venha a dar margem a uma espécie de efeito colateral da mediação, que seria a ocultação de fatos graves, incluindo possível violação de direitos que, eventualmente, viesse a ser deixada em segundo plano, sob o pretexto de que uma solução consensual é sempre mais benéfica para todos os envolvidos.

No aspecto interdisciplinar, por outro lado, pareceu-me que as categorias observadas no trabalho de campo, distinguindo conflitos que são mediáveis de outros que 
não são mediáveis serve como justificativa para decidir pela explicitação ou não dos conflitos, como aconteceu nos casos relatados acima, utilizando de critérios subjetivos. E, nesse caso, o potencial preventivo da mediação parece ficar bastante prejudicado, pois não é possível tratar conflitos que permanecem ocultos.

Qual é a finalidade da mediação no Judiciário? Extinguir processos ou resolver conflitos? A resposta a essa pergunta pode ser determinante para dizer sobre o potencial dessa mediação, agora introduzida no processo civil brasileiro, para evitar reincidências e novas ações.

Incorporar a mediação aos processos judiciais é uma mudança de paradigma bastante significativa. Mas essa mudança exige pensar o processo a partir de outros olhares. Inclusive para afrouxar um pouco a sua rigidez, permitindo experimentar novos caminhos. Isso implica, o meu ver, correr riscos e deixar que nas sessões de mediação a comunicação possa se desenvolver de forma ampla e irrestrita, sem preconceitos, pudores, controles ou amarras (observando, é claro, o limite imposto pelo bom senso e segurança dos seus participantes), e que progrida da forma como desejarem as partes, a fim de que se possa resgatar a sua autonomia e a habilidade de resolver os próprios conflitos.

\section{REFERÊNCIAS BIBLIOGRÁFICAS}

AMORIM, Maria Stella de. Cidadania e jurisdição de direitos nos Juizados Especiais Criminais. In: ___ _ LIMA, Roberto Kant de; BURGOS, Marcelo Baumann. Juizados Especiais Criminais, Sistema Judicial e Sociedade no Brasil. Niterói: Intertexto, 2003, pp. 205-229.

AZEVEDO, André Gomma de (Org.). Manual de Mediação Judicial. Brasília/DF: Ministério da Justiça e Programa das Nações Unidas para o Desenvolvimento. Brasil. 2012.

BARBOSA, Ivan Machado. Fórum de Múltiplas Portas: uma proposta de aprimoramento processual. In: AZEVEDO, André Goma de (Org.). Estudos de Arbitragem, Mediação e Negociação. Brasília: Brasília Jurídica, v. 2, 2003, pp. 243-262.

BRASIL. Lei $n^{o}$ 5.869/1973 - Institui o Código de Processo Civil. Disponível em: <http://www.planalto.gov.br/ccivil_03/leis/L5869.htm>. Acesso em: 15 jan. 2015.

- Lei $n^{o}$ 13.105/2015 - Código de Processo Civil. Disponível em: <http://www.planalto.gov.br/ccivil_03/_Ato2015-2018/2015/Lei/L13105.htm>. Acesso em: 18 mar. 2015.

CAVALIERI FILHO, Sérgio. Você Conhece Sociologia Jurídica? Rio de Janeiro: Forense, 1997.

CEZAR-FERREIRA, Verônica A. da Motta. Família, Separação e Mediação - Uma Visão Psicojurídica. São Paulo: Método, 2007.

FONSECA, Maria Guadalupe Piragibe da. Direito e Interdisciplinaridade. Revista Veredas do Direito. Belo Horizonte. v.2 , n. 3., p 09-15, janeiro, junho de 2005. Disponível em: <http://www.domhelder.edu.br/revista/index.php/veredas/article/ view/113/94>. Acesso em: 20 mar. 2016.

. Iniciação à Pesquisa no Direito: pelos caminhos do conhecimento e da invenção.

Rio de Janeiro: Elsevier, 2009. 
FRAGALE FILHO, Roberto. Quando a empiria é necessária? Anais do XIV Congresso Nacional do CONPEDI. Florianópolis (SC): Fundação Boiteux, 2005, pp. 323-334.

KESSLER, Amalia D. Deciding Against Conciliation: The Nineteenth-Century Rejection of a European Transplant and the Rise of a Distinctively American Ideal of Adversarial Adjudication. Stanford Law Public Working Paper n. 1229249. Stanford Law School, 2009.

MALDONADO, Maria Tereza. O Bom Conflito. São Paulo: Integrare, 2008.

MICHAELIS. Dicionário da Lingua Portuguesa. São Paulo: Melhoramentos. Disponível em: <http://michaelis.uol.com.br>. Acesso em: 10 mar. 2016.

RANGEL, Victor Cesar Torres de Mello. Nem tudo é Mediável. A Invisibilidade dos Conflitos Religiosos e as Formas de Administração de Conflitos (Mediação e Conciliação) no Rio de Janeiro. Dissertação de Mestrado defendida no Programa de Pósgraduação em Antropologia da Universidade Federal Fluminense. Niterói. 2013.

TARTUCE, Fernanda. Técnicas de Mediação. In: SILVA, Luciana Aboim Machado Gonçalves da (Org.). Mediação de Conflitos. São Paulo: Atlas, 2013, pp. 42-57.

WARAT, Luis Alberto. Surfando na Pororoca: ofício do mediador. Florianópolis: Fundação Boiteux, 2004.

Recebido em: 02 de maio de 2016.

Aprovado em: 18 de maio de 2016. 